\title{
Veracruz: monarquía, imperio o república
}

\author{
por \\ Juan Ortiz Escamilla ${ }^{1}$ \\ Universidad Veracruzana
}

Este es un estudio de las propuestas y ensayos de gobierno para México entre 1820 y 1824. Con el restablecimiento de la Constitución de Cádiz, la monarquía absoluta se convirtió en una de tipo constitucional. Una vez que México se independizó con el Plan conservador de Iguala, la nueva nación quedaba subordinada a la monarquía española. La totalidad del proyecto colapsó debido a una división entre sus seguidores, lo que eliminó el llamado imperio mexicano que dio paso al inicio de la primera república federal mexicana.

Palabras clave: México; independencia; imperio; república; monarquía.

Cómo CitAR este artículo / Citation: Ortiz Escamilla, Juan, "Veracruz: monarquía, imperio o república”, Revista de Indias, LXXXI/281 (Madrid, 2021): 183-210. https://doi. org/10.3989/revindias.2021.006.

El restablecimiento de la Constitución de 1812 en la Nueva España generó una verdadera revolución a nivel local y provincial. Los antiguos gobiernos absolutistas militarizados que controlaban la mayor parte de ciudades, villas y pueblos, tuvieron que ceder la autoridad territorial y política a los ayuntamientos y diputaciones provinciales, tal y como se expresaba en la carta gaditana. Para los grupos de poder tradicionales basados en el privilegio, ello representaba una verdadera catástrofe para sus intereses y no se quedaron con los brazos cruzados. Cada uno de los grupos políticos, económicos y territoriales comenzaron a agruparse y a definir su propia agenda. En dicho contexto se pueden identificar a los agentes políticos, militares y económicos empeñados en imponer su proyecto de gobierno: los gaditanos con sus ayuntamientos y diputación

\footnotetext{
1 jortiz@uv.mx, ORCID iD: https://orcid.org/0000-0001-9003-9600
} 
provincial, los partidarios del imperio mexicano, los fieles a la monarquía española y los republicanos.

La historiografía mexicanista del periodo de 1820 a 1824 ha centrado su atención en el restablecimiento de la Constitución de 1812 con sus ayuntamientos y diputaciones provinciales ${ }^{2}$, en la figura de Agustín de Iturbide y su imperio $^{3}$, y se deja en segundo plano la propuesta republicana como forma de gobierno imaginada desde la época del general José María Morelos y retomada a partir de 1820 por dos de sus antiguos subordinados: Guadalupe Victoria en las costas de Veracruz y Vicente Guerrero en las del Pacífico. Tampoco se ha estudiado a fondo a los sectores sociales defensores de la monarquía absoluta y de la constitucional ${ }^{4}$. Cada uno de ellos hizo lo que pudo para alcanzar sus objetivos desde su posición política, económica y militar hasta que se impuso el modelo republicano. Fue en Veracruz donde de momento se definió el futuro modelo de Estado para México 5 .

\section{Y EL FENÓMENO GADITANO}

Cada vez aparecen más evidencias del trasfondo político e ideológico del Plan de Iguala. En primer lugar, se trataba de un levantamiento militar antigaditano en el que se reivindicaba la monarquía como forma de gobierno. En él se reconocía la exclusividad de la religión católica, se ratificaban los derechos y privilegios del clero, del ejército y de las elites novohispanas, y se proclamaba la independencia de la Nueva España para convertirla en el Imperio Mexicano pero subordinado a la Casa de Borbón. Como el mismo Iturbide lo señaló, el Plan no tenía la intención de trastocar el sistema orgánico colonial, sólo deseaba una reforma pacífica del sistema, que convenía a todos $^{6}$. Lo que Iturbide no entendió fue que la guerra y la Carta gaditana habían liberado de la sumisión a los novohispanos quienes entendieron muy bien el propósito del Plan de Iguala. Por ejemplo, los ayuntamientos de las capitales de provincia en principio lo rechazaron por atentar contra los principios básicos de la Constitución, pero tuvieron que ceder ante la amenaza de

2 Ortiz Escamilla y Serrano Ortega, 2007. Annino, 2010. Chust, 2012. Ortiz Escamilla, 2014.

3 Anna, 1991. Arenal, 2010. Moreno Gutiérrez, 2016.

4 Villavicencio, 2015.

${ }^{5}$ Los trabajos más importantes sobre la época de la guerra y consumación de la independencia en Veracruz fueros escritos y publicados en 2008 por Rozat, Jáuregui, Valle Pavón, Serrano Ortega, Chust, Gil Maroño, Ducey, Grafenstein, Ávila, Ortiz Escamilla, Archer, Carbajal López, Del Palacio Montiel. También Jiménez Codinach, 1991. Souto Mantecón, 2001.

6 "Diario de Iturbide", en Gutiérrez Casillas, 1977: 221-223. 
destrucción y saqueo de sus ciudades 7 . Otro testimonio más fue el de Fray Servando Teresa de Mier, que en 1824, al tomar la palabra en la tribuna de la Cámara de diputados, señaló que Iturbide había hecho su revolución por orden de Fernando VII para abolir la Constitución ${ }^{8}$. Lo mismo señaló el gobernador español Francisco Lemaur, quien desde San Juan de Ulúa afirmó que el principal error de Iturbide había sido traicionar a la corona de España, al proclamarse emperador, y por ello había perdido el apoyo de amplios sectores militares y económicos 9 .

No queda la menor duda de que el Plan de Iguala fue un proyecto político elaborado y pensado para preservar los privilegios de las antiguas oligarquías y del clero, bien fuera bajo el amparo de la monarquía española o de la de un gobierno encabezado por ellas mismas, pero sin la participación popular. Los señores del poder, especialmente los de la ciudad de México estaban aterrados ante el enorme dominio alcanzado por ciudadanos envalentonados al ejercer sus derechos políticos concedidos por la Constitución gaditana, y cuya pujanza se expresaba en la multiplicación de nuevas autoridades como ayuntamientos liberales y diputaciones provinciales. La participación de las clases populares, o de su exclusión, en los procesos electorales y de representación política, será el tema central en todos los planes y pronunciamientos militares a lo largo de la primera mitad del siglo XIX.

Desde la formación de la Junta Provisional Gubernativa de 28 de septiembre de 1821, planteada en el Plan de Iguala y en los Tratados de Córdoba, quedaba claro que el proyecto político que representaban era contrario a la Constitución de Cádiz. La formaban 38 notables principalmente de ciudad de México y no de los revolucionarios que durante años habían luchado por la independencia de su país. Más bien los antiguos insurgentes fueron relegados de la estructura del gobierno provisional. Los convocados fueron: el obispo de Puebla, Antonio Joaquín Pérez, cercano al monarca Fernando VII; el consejero de Estado, José Mariano de Almanza; el arcediano de la catedral de Valladolid, Manuel de la Bárcena; el rector de la Universidad y canónigo de la iglesia metropolitana, Matías Monteagudo; el oidor de la Audiencia de México, José Isidro Yáñez; los abogados de la Real Audiencia, Juan Francisco Azcárate, Antonio Gama, Ignacio García Illueca y Juan José Espinosa de los Monteros; y los representantes de la nobleza, el Marqués de Salvatierra, el Conde de la Casa Heras, el Marqués de San Juan de Rayas, el Conde

\footnotetext{
${ }^{7}$ Ortiz Escamilla, 2014: 255-268.

${ }^{8}$ Bustamante, 2001.

9 De Francisco Lemaur al Secretario de Guerra, San Juan de Ulúa, febrero 8 de 1823, Archivo Histórico Militar de Madrid, Madrid (en adelante AHMM), caja 101.
} 
de Jala y Regla y el Marqués de San Miguel de Aguayo. También formaban parte de la Junta el brigadier Manuel de la Sota Riva; el director de Hacienda Pública Manuel Velázquez de León, y el regidor del Ayuntamiento de México Francisco Manuel Sánchez de Tagle, entre otros ${ }^{10}$. Lo mismo sucedió con la publicación de la convocatoria para elegir diputados al Congreso Constituyente de 17 de noviembre de 1821, en la que quedaba implícito el sesgo elitista que representaba a los estamentos privilegiados del ejército, del clero, de la judicatura y de los grandes empresarios ${ }^{11}$.

La alianza estratégica encabezada por la trigarancia y que había logrado el triunfo en muy poco tiempo y sin enfrentamientos armados, comenzó a fracturarse durante la elección de diputados al Congreso Constituyente: en las urnas se expresaron tres posiciones apoyadas por miembros de las fuerzas armadas: los borbonistas, los iturbidistas y los republicanos. Quedaba claro que la suerte del proyecto de Iturbide estaba asegurado en la capital pero no en las provincias. Por ejemplo, en Puebla algunos apoyaban la monarquía absoluta, otros eran constitucionalistas gaditanos, los había en favor de Iturbide y pocos por la república ${ }^{12}$. En cambio, en las provincias de San Luis Potosí, Guadalajara, Zacatecas, Durango y Veracruz los votos se dividieron entre los partidarios de Iturbide y los republicanos ${ }^{13}$.

El Plan de Iguala dejaba muchas dudas sobre su verdadero propósito; se hacía referencia a la independencia mexicana pero ésta quedaba subordinada a la monarquía española, que en ese momento estaba representada por los miles de soldados expedicionarios y novohispanos, distribuidos por todas las provincias, que habían diezmado poblaciones enteras con los llamados castigos ejemplares, que por años habían exigido contribuciones extraordinarias de guerra y que por la fuerza habían hecho leva de sus jóvenes. Resulta inverosímil imaginar que las fuerzas que en el pasado había masacrado a pueblos enteros, fueran ahora reconocidas por los sobrevivientes como sus salvadoras. Los podían tolerar pero no aceptar.

LA PROVINCIA DE VERACRUZ

Desde el momento en que restableció la Constitución en Veracruz, en mayo de 1820, comenzaron los rumores sobre nuevos pronunciamientos ar-

\footnotetext{
10 Alamán, 1985, tomo V: 29-31.

11 Sordo, 2003: 116.

12 Ortiz Escamilla, 2014: 266-268.

13 Sordo, 2003: 118.
} 
mados ahora contra su adopción y en favor de la independencia y de la república como forma de gobierno para México. El antiguo jefe insurgente Guadalupe Victoria salía de su refugio en las montañas, donde herméticamente había sido protegido por los rancheros, para reiniciar su lucha revolucionaria. Con el lema de «Viva la independencia y mueran los serviles que se opongan a ella», el jefe guerrillero convocaba a los pueblos a coger las armas para terminar, "de una vez y para siempre», con la dominación española ${ }^{14}$. Sus emisarios comenzaron a recorrer pueblos, haciendas y rancherías transmitiendo las órdenes y exigiendo lealtad a su antiguo jefe. Los primeros pronunciados fueron los indultados, congregados en los pueblos de San Diego y Temascal, en las inmediaciones de la villa de Córdoba. Los rebeldes destruyeron el pueblo que los realistas les habían obligado a construir. Para el gobernador español tales movimientos eran de «poca importancia» y esperaban pronto terminar con ellos ${ }^{15}$. En Zacatecas, entre los meses de julio y agosto de 1821, en juntas secretas también se puso sobre la mesa la propuesta republicana de Vicente Guerrero. Mariana Terán señala que en ellas se «vitoreaban las voces de república y Vicente Guerrero» ${ }^{16}$. Como ya se apuntó con anterioridad, los republicanos también se visibilizaron en todas las provincias durante las elecciones para nombrar a los miembros del primer Congreso Constituyente.

Es verdad que para la etapa de 1810 a 1821 existe poca información relacionada con el proceso de adopción de las ideas liberales republicanas en Méxi$\mathrm{co}^{17}$. Sin embargo, con la localizada se puede afirmar que en respuesta al liberalismo gaditano, los insurgentes se pronunciaron por el liberalismo republicano. Si bien no existe un programa de gobierno preciso que de testimonio de ello, como el de Bolívar en América del Sur, sí aparecen algunos signos que dan fe de su credo político. El primero fueron los llamados Batallones de la República organizados, no sobre la base de estamentos sociales, sino de individuos diferenciados por sus habilidades en el arte de la guerra. En las hojas de filiación de los soldados, ya no se utilizaron las categorías étnicas que tanto «aborrecían» los constructores de la nueva sociedad; ahora se usaban unas más suaves, como la de «blanco», para los de origen europeo; «rosado», para los indígenas y «trigueño» para los de ascendencia africana ${ }^{18}$. El uso de estas cate-

${ }^{14}$ Manifiesto del general Guadalupe Victoria, sin lugar, enero de 1821, AHMM, caja 92.

${ }^{15}$ Carta de Francisco Hevia al Virrey Conde del Venadito, Córdoba, 4 de enero de 1821 y Carta de Juan Orbegoso al virrey Conde del Venadito, 4 de enero de 1821, AHMM, caja 92.

16 Terán, 2020.

17 Aguilar y Rojas, 2002. Breña, 2006; 2014. Frasquet, 2008.

18 Inspección del Regimiento de Infantería de la República, Huatusco, 19 de enero de 1816, Archivo General de la Nación, México, ramo Operaciones de Guerra (en adelante AGNM, OG), t. 924. 
gorías étnicas aparece en las hojas de servicio de los soldados mexicanos de la primera mitad del siglo XIX, y se omitió la pretendida nobleza de sangre para oficiales promovida durante el imperio de Iturbide. También se reglamentó el ejercicio de tropas ligeras de campaña para los «Regimiento de infantería de la República Mexicana», a cargo del oficial español José Durán desertor de las fuerzas de Fernando Miyares, de Melchor Múzquiz y de Dionisio Mouri. El 24 de agosto de 1816, en Huatusco, también se publicó el proyecto de reglamento para las Provincias Orientales en el que se reconocía a Guadalupe Victoria como «brigadier de los ejércitos mexicanos» ${ }^{19}$.

El general Victoria firmaba manifiestos, correspondencia y cobro de contribuciones de guerra en calidad de «republicano en jefe de la provincia de Veracruz $\rangle^{20}$. Sólo en un escrito a Xavier Mina, Victoria definió su republicanismo como sinónimo de igualdad social, «todos los republicanos, sin distinción de clase». Victoria justificaba su determinación de asumir el gobierno general de la provincia en tanto no hubiera elecciones libres que permitieran elegir un gobierno democrático ${ }^{21}$, lo que nunca consiguió. Otro ejemplo fue el árbol de tamarindo, muy común en la tierra caliente, bautizado como el «símbolo de la libertad», y cada vez que los insurgentes se enfrentaban a los realistas, aseguraban en su sombrero una ramita de dicho árbol para atraer la buena suerte.

La propuesta republicana desapareció con la primera insurgencia, pero no la ilusión de retomar el proyecto. Veracruz fue la primera ciudad donde se juró la Constitución de 1812 y con ello comenzó a desaparecer la tutela de los militares para ceder su lugar a los civiles. También fue la fortaleza de san Juan de Ulúa el último bastión español en rendirse en 1825. Durante todo este tiempo, la ciudad vivió y sufrió de todo. Ante un panorama incierto, en ella se expresaron con mayor fuerza y nitidez las fracturas sociales y económicas, las demandas, los odios, los resentimientos y el reacomodo de viejos y nuevos actores y de fuerzas políticas e ideológicas. Sin importar el lugar de origen, fueran peninsulares, mexicanos o americanos, los hombres hacían política, tomaban posiciones y se asociaban en función de sus respectivos proyectos políticos y económicos.

El 2 de marzo de 1821 se conoció en el puerto la noticia del pronunciamiento militar de Iguala ${ }^{22}$. De inmediato el intendente-gobernador español José Dá-

\footnotetext{
19 Saucedo, 2014: 379-389.

${ }^{20}$ Manifiesto del Republicano Guadalupe Victoria, General en Jefe de la Provincia de Veracruz, Santa Fe sobre Veracruz, 10 de octubre de 1818, AGNM, OG, t. 923.

${ }_{21}$ Carta del general Guadalupe Victoria al general Javier Mina, sin lugar, 1817, citado en Herrejón, 1986, p. 94.

22 Arenal, 2010. Ávila, Ortiz Escamilla, Serrano Ortega y Florescano, 2010. Ortiz Escamilla, 2014. Moreno Gutiérrez, 2016.
} 
vila ordenó la marcha de tropas para la defensa de la ciudad de México. El problema fue que las tropas que iban saliendo de los cuarteles se iban adhiriendo al Plan de Iguala ${ }^{23}$. Los primeros en rebelarse fueron los cuerpos de granaderos de Xalapa que el 14 de marzo en pueblo Perote organizaron la primera fuerza del Ejército Trigarante en la provincia de Veracruz, quedando como primer jefe el teniente coronel José Joaquín de Herrera ${ }^{24}$. De Perote, el 29 de marzo las tropas ocuparon la villa de Orizaba. En este lugar se les sumó Antonio López de Santa Anna ${ }^{25}$ que venía acompañado por una partida de jarochos, negros de la costa. Tres días después se apoderaron de Córdoba, con lo cual se consolidó uno de los frentes nacionalistas más importante de la intendencia. El 13 de abril, Herrera y Santa Anna se separaron con el fin de ampliar las bases de apoyo y las adhesiones al Plan de Iguala. El primero marchó a hacia Puebla y el segundo tomó el camino de la costa. El 20 de abril, cerca de Alvarado, Santa Anna se reunió con el republicano general Guadalupe Victoria y lo reconoció como su jefe «gustoso por el mucho afecto que le profeso a más de los méritos que ha contraído en defensa de la patria» ${ }^{26}$. En este hecho quedaba de manifiesto el oportunismo de Santa Anna al ponerse bajo las órdenes de un exinsurgente cuando él siempre había militado en el bando contrario.

Desde el mes de marzo la plaza de Veracruz perdió toda comunicación con la ciudad de México. Nada se sabía de la situación de las provincias del interior porque los caminos estaban controlados por los rebeldes y la correspondencia pública y privada estaba detenida en el puerto de Veracruz. Para el mes de junio la mayor parte de las localidades de la intendencia habían desconocido al gobierno de España y reconocido al emanado del Plan de Iguala ${ }^{27}$.

${ }^{23}$ Carta del gobernador José Dávila al Ministro de la Guerra, Veracruz, 19 de abril de 1821, AHMM, caja 5375.

${ }^{24}$ En 1809 Herrera ingresó al ejército español como cadete del regimiento Corona y combatió a los insurgentes por varios años y en 1820 pidió su retiro. Hoja de servicio del general José Joaquín de Herrera, Archivo Histórico de Cancelados de la Secretaría de la Defensa Nacional, México (en adelante AHCSDN), exp. III/1-33.

${ }^{25}$ Antonio López de Santa Anna nació el 21 de febrero de 1795 en la villa de Xalapa. El 6 de julio de 1810 ingresó como cadete en el Regimiento de Infantería de Línea de Veracruz. Combatió a la insurgencia del norte de Nueva España y a la de Veracruz. Como lo ha señalado Will Fowler, de la convivencia con los exinsurgentes indultados nació la amistad entre Santa Anna y sus antiguos enemigos. Fowler, 2010: 73.

${ }^{26}$ Carta de Antonio López de Santa Anna a Agustín de Iturbide, Alvarado, 25 de abril de 1821, Archivo Histórico de la Secretaría de la Defensa Nacional, México (en adelante AHSDN), exp. 174, fs. 9-10. Carta de Santa Anna a Guadalupe Victoria, Alvarado, 25 de abril de 1821, AHSDN, exp. 174, f. 40.

27 Carta de José Dávila al Secretario de Guerra, Veracruz, 10 de junio de 1821, AHMM, caja 5375 . 
El 23 de junio las tropas de Santa Anna sitiaron la ciudad. Con ello daba inicio el episodio más dramático que hasta entonces había vivido la población veracruzana, al convertirse en el botín de muchos intereses y de pocos fieles y desinteresados defensores. Como veremos más adelante, la salvaguarda de los bienes de los españoles marcó el rumbo de los acontecimientos y determinó el futuro de las negociaciones. Ello explica que en el puerto se organizara la resistencia más fuerte y prolongada contra los españoles.

Todo era confusión en la ciudad, sitiada y sin suficientes tropas para defenderla; el comercio estaba paralizado y las autoridades dudaban en tomar cualquier decisión. Fue por ello que el 3 de junio, el intendente José Dávila ante el Ayuntamiento asumió las facultades de Capitán General y Jefe Superior Político de Nueva España, mientras llegaba el designado por las Cortes ${ }^{28}$. Después de un penoso viaje de 61 días, de Cádiz a Veracruz, Juan de O'Donojú arribaba al puerto sin tropas ni dinero. Y como buen político, prefirió negociar una salida a la crisis para evitar una ruptura definitiva. Después de haber jurado la Constitución en calidad de Jefe Superior Político y Capitán general de Nueva España se dirigió al jefe del Ejército Trigarante Agustín de Iturbide en busca de diálogo y éste lo aceptó. El primer resultado favorable por esta acción fue la suspensión del asedio contra la plaza; las puertas del recinto se abrieron al libre tránsito de personas, de correspondencia y de víveres ${ }^{29}$. También ingresaron las tropas encabezada por Santa Anna.

O'Donojú e Iturbide se reunieron en la villa de Córdoba, una población alejada de la costa y ubicada en las faldas de la montaña de nombre Pico de Orizaba. Ambos firmaron unos Tratados en los que se reconocía la independencia del Imperio Mexicano y una forma de gobierno Monárquico constitucional moderado. Se ratificaba el ofrecimiento para ocupar el trono, en primer lugar, a Fernando VII; en segundo, al infante don Carlos, y en orden progresivo sucesorio continuaban los infantes, don Francisco de Paula o don Carlos Luis. Si ninguno de ellos aceptaba, serían las Cortes del Imperio Mexicano las encargadas de designar a quien ellas consideraran ser el indicado. Mientras tanto, se acordó formar una Junta Provisional Gubernativa para que nombrara a los miembros de una regencia encargada del poder ejecutivo, y que ésta a su vez convocara a elecciones generales para diputados a Cortes. Tanto los europeos como los americanos quedaban en libertad de fijar su residencia

28 Acta del Ayuntamiento Constitucional de Veracruz, Veracruz, 28 de julio de 1821, AHMM, caja 5375. Fernández, 1992: 231-234.

${ }^{29}$ Carta de Juan de O'Donojú al Ministro de Guerra, Veracruz, 13 de agosto de 1821 y Carta de Antonio López de Santa Anna a Juan de O'Donojú, Campo de Extramuros de Veracruz, agosto de 1821, AHMM, caja 5375. 
donde lo decidiesen. En cambio, los peninsulares desafectos con la independencia mexicana debían abandonar el territorio. Finalmente, las tropas acantonadas en la ciudad de México debían abandonar sus posesiones sin hacer resistencia alguna ${ }^{30}$.

La firma de los Tratados de Córdoba dividió aún más a las tropas expedicionarias que todavía no salían de las plazas de México. Agrupados entre los partidarios de la Constitución gaditana y los defensores del absolutismo, obligó al general Dávila a desconocer la autoridad de O’Donojú, no sólo como capitán general, sino también como «ciudadano español» por haber puesto a disposición de Iturbide todas las plazas del reino y proclamar la independencia de sus territorios. Cuatro días después, es decir, el 8 de octubre, O’Donojú caía gravemente enfermo y moría defendiendo la causa mexicana ${ }^{31}$. Cuando la situación se vio perdida en la plaza de Veracruz, Dávila sabía que tenía que abandonar la ciudad para atrincherarse en la fortaleza de san Juan de Ulúa. Pero dudaba en entregarla a las tropas de Santa Anna, conformada por «llamados Jarochos de estas cercanías, milicia irregular, semibárbara y que no ansía más que el robo», sólo pensaban en saquearla ${ }^{32}$.

La llegada al puerto del exrealista, coronel Manuel Rincón, aceleró la salida de las tropas españolas. Dávila no quería entregar la plaza a Santa Anna para no darle más poder ya que se había autoproclamado comandante general de la provincia de Veracruz. Una vez que las tropas españolas abandonaron la ciudad, ésta se convirtió en rehén de varias fuerzas, intereses y grupos que intervenían en las negociaciones y solución de los asuntos de interés común: el ayuntamiento, las tropas españoles de San Juan de Ulúa divididas, entre absolutistas y liberales, los comerciantes del consulado también enemistados con los partidarios del libre comercio y los del monopolio español ${ }^{33}$, la diputación provincial, los jarochos encabezados por Santa Anna y Guadalupe Victoria, y las casas comerciales inglesas, norteamericanas y francesas.

${ }^{30}$ Copia del Acta de firmada en la villa de Córdoba, 24 de agosto de 1821, AHMM, caja 5375 .

${ }^{31}$ Carta de José Dávila a Juan de O'Donojú, Veracruz, 4 de octubre de 1821 y Carta de José Dávila al Secretario de Guerra, Veracruz, 10 de octubre de 1821, AHMM, caja 5375. Carta de Pascual de Liñán al Ministro de Guerra, México, 10 de octubre de 1821, AHMM, caja 5376. Carta de José Dávila a Domingo Estanislao de Luaces, San Juan de Ulúa, 24 de febrero de 1822, AHSDN, exp. 206, fs. 141-142.

${ }^{32}$ Carta de José Dávila al Secretario de Guerra, Veracruz, 10 de junio de 1821, AHMM, caja 5375.

33 Jiménez Codinach, 1991. Souto Mantecón, 2001. 
LA GUERRA DE BAJA INTENSIDAD: TODOS CONTRA TODOS

La salida de las tropas de la ciudad las separó geográficamente de las mexicanas y definió con mayor claridad las posiciones de los bandos: los españoles en San Juan de Ulúa y los mexicanos en la ciudad de Veracruz. Sin embargo, nada estaba escrito. Apenas se había dado el primer paso, y como en una tabla de ajedrez, todos los actores movían sus piezas. Para empezar, los generales de La Habana le restaron importancia a Veracruz al modificar el estatus que antes había tenido y quedó como «una posesión más de Ultramar» ${ }^{34}$, lo que redujo, en gran medida, los posibles auxilios enviados desde la isla. Por ejemplo, en vez de los 834 soldados y los 100 artilleros ordenados por el rey, sólo se envió la mitad y llegaron con retraso.

Las alianzas que Iturbide había hecho para alcanzar el poder pronto se disolvieron, más aún desde el momento en que desconoció el Congreso Constituyente y se proclamó emperador. Para el nuevo gobernador de la fortaleza de Ulúa, Francisco Lemaur, el error de Iturbide había sido adoptar una política contraria a los intereses de los españoles con tal de mantener su imperio por lo que se convirtió en el principal enemigo a derrotar ${ }^{35}$. A finales de 1822 , la ciudad de Veracruz era rehén de tres fuerzas armadas anhelaban poseerla: la «jarochada» con Santa Anna a la cabeza, que de hecho estaba dentro del recinto; las españolas con el gobernador Francisco Lemaur que desde la isla de San Juan de Ulúa controlaban las entradas por mar y le apuntaban con sus cañones, y las iturbidistas ahora encabezabas por el español José Antonio de Echávarri que desde el casamata de Santa Fe protegían los caminos reales ${ }^{36}$. Lo fascinante de esta historia es que ninguna de las tres fuerzas podía sobrevivir y mantenerse en sus posiciones sin el apoyo de por lo menos una de las otras dos. Como veremos más adelante, las tres fuerzas utilizaron todo tipo de alianzas y argucias para debilitar a sus oponentes y quedarse con el control de la ciudad. Lo paradójico del asunto fue que al final de la guerra ninguno de los tres jefes logró su objetivo. El hecho de que todos los actores involucrados en el conflicto mantuviera comunicación entre sí, que unos a otros revelaran sus planes, que todos aseguraran tener la verdad absoluta sobre los

${ }^{34}$ Acta de la Junta de Generales, La Habana, 14 de noviembre de 1821, Archivo General de Indias, Sevilla (en adelante AGI), Cuba, leg. 2115, fs. 5-6v.

${ }_{35}$ Carta de Francisco Lemaur al Secretario de Guerra, San Juan de Ulúa, febrero 8 de 1823, AHMM, caja 101.

36 José Antonio de Echávarri nació el 18 de mayo de 1789 en Vizcaya. En 1810 se unió el ejército contrainsurgente encabezado por Calleja en San Luis Potosí. Fue en ésta época cuando se hizo muy amigo de Iturbide. Hoja de servicio del general José Antonio de Echávarri, AHCSDN, exp. XI/111/1-69. 
acontecimientos, etcétera, terminó por generar tal confusión, que al final nadie sabía a ciencia cierta lo que estaba ocurriendo ${ }^{37}$.

Francisco Lemaur urdió la enemistad de Santa Anna con Echávarri. Incluso inventó, y todos le creyeron, que el primero pretendía asesinar al segundo ${ }^{38}$. Después Lemaur escribió a Echávarri para establecer un acuerdo sobre las futuras relaciones entre el castillo y la ciudad pero sin la participación de Santa Anna. A esta iniciativa se sumó el ayuntamiento, pero no prosperó ante la negativa de la diputación provincial y de Iturbide. Según Lemaur, ello se debía en parte a la "emulación y odio que siempre tuvieron contra los veracruzanos los de México que miraron con indiferencia y aún con satisfacción la ruina de esta plaza». De allí que el mejor aliado de Lemaur fueran los veracruzanos con propiedades en la ciudad ${ }^{39}$.

El emperador, aunque lo intentó, no logró sacar a Santa Anna del puerto para que pasara a la ciudad de México. Como reacción éste optó por lanzar su plan republicano el 2 de diciembre de 1822. Desde entonces Santa Anna tuvo el control pleno de la ciudad, Echávarri se mantuvo en la cercana hacienda de Santa Fe y los españoles conservaron el castillo de San Juan de Ulúa. Esta situación facilitó a Lemaur continuar con sus intrigas y convenció a la Diputación Provincial y al Ayuntamiento de que el castillo era su único escudo protector para no ser atacados por las tropas imperiales de Iturbide. Por el momento, Lemaur sacaba ventaja frente a sus adversarios porque dejaba de ser el blanco de los ataques y se ponía en el papel de mediador en el conflicto. Ahora preparaba otro plan para lograr la destitución del «usurpador del trono de México». Para ello se requería de la «astucia política a fin de llevar a su término la deposición o muerte de Iturbide $»^{40}$.

Una vez iniciada la nueva crisis ahora entre las tropas mexicanas, de inmediato Echávarri quiso conocer la posición del jefe español. Éste reconoció estar detrás del pronunciamiento de Santa Anna y se comprometió a retirarle su apoyo a cambio de que Echávarri le brindara mayores garantías «acerca de toda ulterior desistencia del sitio y bloqueo del castillo, que aunque al parecer justas, no podía prestar el sitiador, mientras sus tropas sufrían las mayores molestias en un territorio donde la naturaleza parece había reunido toda especie de plagas

${ }^{37}$ Carta de José Antonio de Echávarri al Ministro de Guerra y Marina, sin lugar, 9 de enero de 1823, AHMM, caja 101.

${ }^{38}$ Carta de Francisco Lemaur al Rey, Madrid, 27 de noviembre de 1826, Archivo General Militar de Segovia, Segovia (en adelante AGMS), leg. L-578.

${ }^{39}$ Carta de Francisco Lemaur al Secretario de Estado, Castillo de San Juan de Ulúa, 6 de noviembre de 1822, AHMM, caja 100.

${ }^{40}$ Idem. 
para atormentar a los hombres». En el informe que dio al monarca, Lemaur reconoció que las tropas de Echávarri «eran muy adictas al emperador», no así los oficiales peninsulares a su servicio y que mantenían una relación estrecha con el castillo de Ulúa. Ellos fueron los primeros en presionar a Echávarri para se declarase contra de Iturbide. «Todo aquél ejército alzó sus pendones contra Iturbide, siguiendo sin confesarlo el partido de Santa Anna». Lemaur se jactaba de sus habilidades diciendo que con su arte había logrado «dividir primero en su provecho, y reunir después en sus miras a los generales enemigos $»^{41}$.

\section{De San Juan de Ulúa al campamento de Casamata}

En el contexto de las alianzas, el pronunciamiento implicó un nuevo reposicionamiento de las partes involucradas: Santa Anna, Guadalupe Victoria, la Diputación Provincial, el Ayuntamiento de Veracruz y las guarniciones de Alvarado y La Antigua se manifestaron por el plan republicano; en su contra se expresaron las tropas de Iturbide encabezadas por el general Echávarri y la mayor parte de los ayuntamientos y milicias de la provincia. Por su parte, el gobernador Lemaur se mantuvo neutral, tal y como lo había previsto, y una vez logrado el enfrentamiento entre Santa Anna y Echávarri, se dio a la tarea de «hacer recaer toda la odiosidad sobre Iturbide» y de buscar un acercamiento con Echávarri para separarlo de los intereses del emperador ${ }^{42}$.

En el puerto, el pronunciamiento cogió por sorpresa a todos sus habitantes. El ayuntamiento y la Diputación se adhirieron presionados por los militares y en la creencia de que habría manifestaciones de apoyo en todas las provincias. Las corporaciones también cedieron ante el compromiso de Lemaur de no atacar la ciudad, de defender a Santa Anna y de garantizar el comercio. Por su parte, éste hizo creer a Lemaur que seguiría sus consejos para las operaciones militares que emprendiese contra Echávarri. La realidad fue otra: por ejemplo, Santa Anna no guarneció Alvarado para asegurar el envío de víveres al castillo; tampoco dejó en dicho lugar las goletas Iguala y Anáhuac con sus ocho balandras sino que se las llevó al puerto, y sólo desmontó una parte de la artillería de Antón Lizardo ${ }^{43}$.

\footnotetext{
${ }^{41}$ Carta de Francisco Lemaur al Rey, Madrid, 27 de noviembre de 1826, AGMS, leg. L-578.

${ }^{42}$ Carta de Francisco Lemaur al Secretario de Estado, Castillo de San Juan de Ulúa, 22 de diciembre de 1822, AHMM, caja 100.

${ }^{43}$ Carta de Francisco Lemaur al Secretario de Guerra, San Juan de Ulúa, 29 de enero de 1823, AHMM, caja 101.
} 
En el bando imperial, las órdenes dadas por Iturbide como acabar con Santa Anna y atacar el castillo de San Juan de Ulúa tampoco se cumplieron. Su jefe de operaciones, Echávarri, mejor optó por la no-agresión, por la negociación, y postergó el ataque hasta la supuesta expulsión de Santa Anna de la ciudad y a la habilitación de los barcos de la escuadra mexicana cuyas condiciones eran realmente lamentables, sin tripulación y sin recursos para su reparación. Lo cierto era que Echávarri ya no estaba tan de acuerdo con la política exterior de Iturbide, veía en ella serias contradicciones: por un lado el emperador deseaba que el gobernador de Ulúa le entregara la fortaleza sin tomar en consideración que este jefe sólo cumplía las órdenes de su gobierno y era con éste con quien había tratar el asunto; por el otro, se rehusaba a negociar un armisticio por considerarlo un «paso denigrante». Además, el gobierno de Iturbide no contaba con los medios económicos, militares y humanos para hacer valer su autoridad tanto en la ciudad como en la isla de San Juan de Ulúa ${ }^{44}$. Echávarri pensó que Veracruz caería rendida con sólo aproximarse hasta sus puertas, pero no fue así; de nada le valió presionar al ayuntamiento para que desconociera a Santa Anna y le entregara la plaza.

Por lo general, la historiografía ha centrado su atención en las diferencias entre Santa Anna e Iturbide, y de los argumentos utilizados por ambos para desprestigiarse mutuamente; sin embargo, poco se conoce la versión española de los acontecimientos, que viene a ser realmente reveladora. Como se recordará, desde que los peninsulares abandonaron la ciudad de Veracruz, éstos se convirtieron en especialistas de la intriga, armando proyectos y planes subversivos con el fin de asegurar su frágil posición en el castillo de Ulúa. Desde que apareció Echávarri en las goteras de la ciudad, Lemaur comenzó a fraguar un plan, como lo había hecho con Santa Anna, ahora para destruir a Iturbide. Para ello debía ganarse la confianza de Echávarri, convencerlo de que la mejor manera de salvar a México era restablecer el congreso disuelto por el emperador. Así se hizo, y funcionó porque se formó «un partido más poderoso y de más crédito que el capitaneado por Santa Anna» ${ }^{45}$.

Para el 10 de diciembre de 1822, Echávarri comenzó a mostrar cierta ambivalencia entre su lealtad a México, a España o, por qué no decirlo, a los dos países. Él estaba consciente de su contribución a «la libertad de este suelo», pero también era cierto que su lealtad a España le obligaba a buscar las

${ }^{44}$ Carta de José Antonio de Echávarri al Ministro de Guerra y Marina, sin lugar, 9 de enero de 1823, AHMM, caja 101.

${ }^{45}$ Carta de Francisco Lemaur al Secretario de Guerra, San Juan de Ulúa, 29 de enero de 1823, AHMM, caja 101. 
mejores ventajas para su patria ${ }^{46} . ¿ Q$ Que hacer en momentos tan críticos? En cierto modo justificó su posición al arremeter contra Santa Anna y lo hizo responsable de los sucesos del 27 de octubre, cuando los españoles desembarcaron en las playas de Veracruz, sin que él hubiese tenido tiempo de frenarlo. Lo que sí pudo evitar fue el hundimiento de los buques existentes en la bahía ordenado por Santa Anna, «a cuyo efecto había dado ya la orden al oficial de artillería» pero éste lo consultó con Echávarri y en el acto hizo suspender su ejecución. Para este jefe, la mejor manera de resolver el conflicto, que era su mayor interés, era procurar la «unión y la armonía con la España, según se había prometido en el Plan de Iguala» ${ }^{47}$.

Lemaur también le informó a Santa Anna del nuevo plan que se estaba formando con Echávarri y estuvo de acuerdo con el restablecimiento del Congreso disuelto y de acatar las decisiones que de él emanaran, pero no dejaba de recelar las propuestas de sus adversarios por la estrecha relación que habían establecido entre sí. Y no era para menos, Lemaur y Echávarri buscaron la manera de neutralizarlo pero no lo consiguieron. A pesar de la gran desconfianza que imperaba (porque en tales circunstancias no se sabía con precisión quien era aliado y quien enemigo disfrazado) y de las deserciones que iban en aumento, las tropas de Santa Anna comenzaron a dudar sobre la efectividad de resistir ante un eventual asalto. Éste ocurrió el 2 de enero de 1823. Las tropas imperiales atacaron la ciudad y, para sorpresa de todos, los jarochos de nueva cuenta sacaron la casta, de la que tantos elogios habían recibido en el pasado, y rechazaron la agresión provocando en el bando imperial 70 bajas entre muertos, heridos y prisioneros ${ }^{48}$.

La acción fortaleció los ánimos de los republicanos, contuvo las deserciones y dio confianza del triunfo a la tropa. Santa Anna tenía razón al asegurar que para Echávarri la ciudad y sus habitantes no merecían ningún respeto.

46 Carta de José Antonio de Echávarri a Francisco Lemaur, Xalapa, 10 de diciembre de 1822, AHMM, caja 100.

47 Carta de Antonio Fraga a Francisco Lemaur, San Juan de Ulúa, 14 de diciembre de 1822; carta de José Antonio de Echávarri a Francisco Lemaur, Xalapa, 10 de diciembre de 1822, AHMM, caja 100.

${ }^{48}$ Carta de Francisco Lemaur al Secretario de Guerra, San Juan de Ulúa, 29 de enero de 1823, AHMM, caja 101. Según Lucas Alamán, Echávarri fracasó por la cobardía de las tropas que se resistían a luchar. Además, porque «las tropas empleadas en el sitio no llegaban a tres mil hombres, mucha parte de ellas de caballería, y por tanto poco útiles para tal empresa; que la artillería era de campaña y no del calibre suficiente para abrir brecha, ni aun en aquellas débiles murallas, y que los soldados sin tiendas ni otro abrigo, como sucede siempre en los ejércitos mexicanos, sufrían mucho de un temperamento al que no estaban acostumbrados, carecían de socorro y aún estaban escasos de víveres». Alamán, 1985, t. 5: 707. 
Ésta fue la razón principal por la que las tropas imperiales no pudieron ocupar la plaza de Veracruz. Más tarde, Echávarri y el coronel José María Lobato fraguaron una trampa para emboscar a Santa Anna pero no lo consiguieron. Durante los siguientes dos meses, en vez de enfrentamientos armados las partes continuaron negociando hasta conseguir los acuerdos plasmados en el Plan de Casamata. El 15 de enero de 1823, en voz de su secretario Arana, Echávarri hizo saber a Lemaur su punto de vista sobre las conversaciones tenidas con anterioridad: estuvo de acuerdo en restablecer el Congreso y en darle plena libertad para deliberar y elegir la forma de gobierno que mejor se adoptase al país; pero se negó terminantemente a establecer trato alguno con Santa Anna, y menos a figurar unido a él en la nueva revolución. Una vez destruidos los obstáculos que representaban tanto Santa Anna como Iturbide, entonces Echávarri firmaría con Lemaur un armisticio «que encaminase a una pacificación con la España y le sería no menos ventajoso que a este país ${ }^{49}$.

Si bien, el Plan de Casamata fue principalmente obra de los jefes españoles más importantes por su peso político y militar con residencia en México, tampoco era tan fácil llevarlo a la práctica sin el consentimiento de los otros jefes y demás corporaciones. En las discusiones sobre la elaboración del Plan se expresaron los puntos de vista de la mayoría de ellos hasta alcanzar el acuerdo de convocar a un congreso cuyos miembros destacaran por sus ideas liberales. Según Lemaur, Echávarri sostuvo la posición «menos ofensiva al emperador»; Santa Anna ya se había lanzado en su contra y a Guadalupe Victoria lo que más le «repugnaba», no era tanto Iturbide como persona sino la figura de emperador que representaba. Él se mantuvo aferrado a su proyecto republicano como forma de gobierno ${ }^{50}$.

Una vez alcanzado el acuerdo entre los jefes españoles, Echávarri puso a consideración de sus tropas el «Plan Restaurador», y durante varios días discutieron cada uno de los artículos hasta lograr el consenso de todos los oficiales. Los jefes que lo firmaron estaban conscientes de que no era tan sencillo arremeter contra el caudillo mientras durase el «delirio por la independencia», menos aún que el «orgullo y la soberbia» de Iturbide le permitiesen someter la corona al juicio de un congreso enemigo. Lemaur inició una amplia campaña en descrédito del emperador y a favor del plan militar ${ }^{51}$. El siguiente paso fue ganar el apoyo de la diputación y del ayuntamiento

${ }^{49}$ Carta de Francisco Lemaur al Secretario de Guerra, San Juan de Ulúa, marzo 8 de 1823, AHMM, caja 101.

${ }_{50}$ Carta de Francisco Lemaur al Secretario de Guerra, San Juan de Ulúa, marzo 8 de 1823, AHMM, caja 101.

${ }^{51}$ Idem. 
hasta alcanzar la suspensión del sitio sobre la ciudad por parte de Echávarri, la destitución de Santa Anna de la comandancia general y la adhesión al plan de todas las corporaciones de la provincia. En ningún momento se propusieron hostilizar a los españoles de Ulúa ${ }^{52}$. Con la firma de dicho Plan, la Diputación cobró importancia al ser elevada por los militares al rango máximo de autoridad en la provincia e incluso hicieron los honores.

Un aspecto que no debemos perder de vista es que el plan se armó en el contexto de las mayores bajas en el bando imperial ocasionadas por las enfermedades propias de la tierra caliente y de las inclemencias de los fuertes vientos del norte pues se encontraban en campo raso. Los daños eran más funestos que las exiguas acciones de guerra que habían librado ${ }^{53}$. En la misma situación se encontraban los españoles del castillo de San Juan de Ulúa que sufrían los estragos del «vómito prieto» y del escorbuto, no así las tropas de Santa Anna, los Jarochos, que estaban acostumbrados a estos climas, pero ya no contaban con el apoyo del castillo ni de las corporaciones de la ciudad.

El primero de febrero de 1823, se firmó el Plan de Casamata y al día siguiente Lemaur lo tenía en sus manos, acompañado de una carta de Echávarri en la que aceptaba la propuesta para juntos «cimentar las relaciones de este país con la España ${ }^{54}$. Con la firma del Plan, los españoles estaban logrando arrancar de las «sienes de Iturbide la corona que se atrevió a ceñirse quitándola de las de Vuestra Majestad». También lograron el embarque hacia el

52 Carta de Echávarri al Ayuntamiento de Veracruz, Campo sobre Veracruz, 9 de enero de 1823, Archivo Histórico Municipal de Veracruz, Veracruz (en adelante AHMV), caja 144, vol. 189, fs. 186-187. Echávarri prometió «evitar la efusión de sangre», lo que «debe ser obra de la razón, me contenté con aproximar mis fuerzas a esa plaza no dudando que Santa Anna adoptaría el partido que dictan la prudencia y los sentimientos filantrópicos, de que tanto blasona, pero he visto con dolor que, empeñado en sostener su capricho, todo lo pospone, sin tomar en cuenta los males que va a ocasionar», Carta del Ayuntamiento a Echávarri, Veracruz, 1 de febrero de 1823, AHMV, c. 144, vol. 189, f. 189. Carta del Comandante de Alvarado José de Aldana a Echávarri, Alvarado, 3 de febrero de 1823, AHMV, c. 144, vol. 189, f. 200. Orden de Gregorio de Arana al Regimiento de la plaza, Alvarado, 3 de febrero de 1823, AHMV, c. 144, vol. 189, fs. 202-203. Carta del comandante de Orizaba y Córdoba a Echávarri, 3 de febrero de 1823, AHMV, c. 144, vol. 189, fs. 206-210. Carta de José María Calderón a Echávarri, Puente Nacional, 6 de febrero de 1823, AHMV, c. 144, vol. 189f. 213.

${ }_{53}$ Carta de Francisco Lemaur al Secretario de Guerra, San Juan de Ulúa, 29 de enero de 1823, AHMM, caja 101.

${ }^{54}$ Carta de José Antonio de Echávarri a Francisco Lemaur, Casamata, febrero 2 de 1823 , y Carta de Francisco Lemaur a José Antonio de Echávarri, San Juan de Ulúa, febrero 2 de 1823, AHMM, caja 101. 
castillo de más de diez millones de pesos en dinero, víveres y efectos precio$\operatorname{sos}^{55}$.

Una día después de proclamado el Plan, Santa Anna lo secundó, consiguiendo con ello salir de la ciudad de una manera más o menos decorosa. En menos de seis días se manifestaron por el mismo la diputación provincial, así como los ayuntamientos y comandancias militares de Veracruz, Alvarado, Córdoba, Orizaba y Puente Nacional. Al mismo tiempo, por primera vez el ayuntamiento de Veracruz se declaraba abiertamente liberal y facilitaba a los militares la cantidad de diez mil pesos con cargo a los derechos de aduana ${ }^{56}$. Sin Santa Anna de por medio, y bajo la bandera del liberalismo, se concretó la alianza entre las autoridades locales y el gobierno militar nacional en contraposición a los situados en el castillo de Ulúa quienes se habían declarado abiertamente por la monarquía. Después del pronunciamiento, las negociaciones continuaron entre los jefes allí reunidos; si bien, todos estaban de acuerdo en la desaparición de la monarquía mexicana, Echávarri, Cortazar y otros oficiales permanecían leales a Iturbide, pero al final dominaron los republicanos encabezados por Guadalupe Victoria ${ }^{57}$.

Los españoles absolutistas habían logrado que en el plan no se tocaran los intereses de los peninsulares y con ello la mayoría habían ganado tiempo para ponerlos a salvo. Sin embargo, los acontecimientos tomaron un rumbo distinto al esperado. Se suponía que Echávarri marcharía a Puebla, sede de la capitanía general de las provincias de Puebla, Veracruz y Oaxaca, para entregar

${ }^{55}$ Informe de Francisco Lemaur al Rey, Madrid, 27 de noviembre de 1826, AGMS, leg. L-578.

56 Acta de Cabildo de 17 de febrero de 1823, Archivo Histórico Municipal de Xalapa (AHMX), fs. 25-26; Acuerdo del Ayuntamiento de Veracruz, 12 de julio de 1823, AHMV, c. 144, vol. 189, f. 292.

57 Según Lemaur, Guadalupe Victoria se había convertido en toda una leyenda: «baste decir que en su robusta juventud, al estallar por primera vez la guerra de la independencia se hallaba estudiando en un colegio de la capital de donde desertó, y haciendo primero ensayo de su persona para endurecerla en los trabajos de la guerra, la siguió después con la mayor constancia, y al dejar las armas en el tiempo que apareció todo pacificado, más bien que acogerse a un indulto se redujo a vivir escondido por más de dos años en una cueva, alimentándose solo de plantas silvestres. Sencillo en su porte, y sin aparente ambición y de entendimiento algo cultivado parece que le anima solo el delirio de ver el gobierno de su país independiente del de España; y habiendo llevado este solo objeto en su antiguo alzamiento, trató siempre bien a sus prisioneros, aunque no se daba cuartel en la guerra que entonces se hacía. Su constancia nada común entre sus paisanos, la firmeza en sus principios y la opinión de valiente le adquirieron un crédito sobre todo en esta provincia del que necesitaba Santa Anna para su partido y fue lo que le hizo ceder a Victoria el mando superior». Carta de Francisco Lemaur al Secretario del Despacho, Castillo de San Juan de Ulúa, 8 de marzo de 1823. AHMM, caja 101. 
el mando de la revolución al general José Morán, por ser uno de los criollos más comprometidos con su causa y para evitar las imputaciones de Iturbide en el sentido de que, como Echávarri era peninsular, estaba coludido con Lemaur para destruirle ${ }^{58}$. Desde Puebla se convocaría a los antiguos diputados a Cortes para que sesionaran, no en la ciudad de México, sino en Tehuacán. Desde la primera sesión los diputados debían declarar «rebelde a Iturbide, y de este modo acabar de perderlo en la opinión pública». Su plan se vino abajo ante la reacción de los «léperos contra los españoles que en la noche temieron ser asaltados en sus propias casas $\rangle^{59}$. Al mismo tiempo, la opinión pública se fue inclinando hacia la independencia definitiva y hacia el sistema republicano como forma de gobierno. Además, Echávarri fue depuesto del mando político y militar de Puebla y su lugar lo ocupó el general Manuel Gómez Pedraza ${ }^{60}$.

Casamata también dio pie al inicio de las negociaciones entre el gobierno liberal español y el mexicano que se estaba conformando. Desde el 13 de febrero de 1822, las Cortes habían nombrado comisionados ante los gobiernos establecidos en las provincias de Ultramar con el propósito de «oír y recibir las proposiciones que se les hicieren para transmitirlas a la Metrópoli, exceptuando aquellas que quitasen o limitasen de cualquier modo a los españoles europeos y americanos la libertad de trasladar y disponer de sus personas, familias y propiedades como mejor les convenga ${ }^{61}$, lo cual no había sucedido en México.

Los comisionados tardaron nueve meses en llegar a costas mexicanas. Para entonces las fuerzas políticas y militares debatían sobre la pertinencia o no de continuar con el apoyo a Iturbide y sobre la adopción del sistema liberal como forma de gobierno. La delegación española la encabezaba Juan Ramón de Osés, antiguo Magistrado de la Audiencia de México, el brigadier Santiago Irrisarri y como secretario Blas Osés, hijo del primero. Los comisionados permanecieron en el Castillo de San Juan de Ulúa hasta la caída del gobierno de Iturbide y el restablecimiento del Congreso mexicano, el cual nombró como sus representantes para las negociaciones al general Guadalupe Victoria y al diputado por Veracruz José María Serrano.

58 Tecuanhuey, 2003: 476-484.

59 Carta de Francisco Lemaur al Secretario del Despacho, Castillo de San Juan de Ulúa, 8 de marzo de 1823, AHMM, caja 101.

${ }^{60}$ Alamán, 1985, t. 5: 779.

${ }^{61}$ Carta de Juan Ramón Osés a Guadalupe Victoria, Castillo de San Juan de Ulúa, 20 de abril de 1823 y Decreto de las Cortes, 13 de febrero de 1822, Archivo Histórico de la Secretaría de Relaciones Exteriores de México, México, vol. 1-F 2183. 
El 20 de abril de 1823 los comisionados españoles establecieron comunicación con el general Victoria, a quien le manifestaron que las Cortes y el Gobierno español deseaban «terminar las disensiones entre Nueva España y la Antigua España de un modo ventajoso a los dos países». Por su parte, Victoria le expresó la coincidencia en sus sentimientos «en el orden de entablar relaciones de estrecha amistad y recíproca conveniencia entre el gobierno de Su Majestad las Cortes y la Nación Mexicana ${ }^{62}$. Desde este primer acercamiento se definieron las posiciones ambos comisiones. De una manera deliberada utilizaron lenguajes que reflejaban exactamente el significado de sus palabras. Mientras que los mexicanos buscaban el reconocimiento de su independencia, los españoles sólo estaban autorizados para celebrar «tratados provisionales de comercio». Lo paradójico, en el caso de México, era que éste no se había interrumpido y tampoco había enfrentamientos armados; «por conveniencia mutua se observaba un pacto de no-agresión». Lo que más preocupaba a los españoles era la llegada de los comisionados de Estados Unidos e Inglaterra con la misión de entablar pláticas para la firma de tratados comerciales y de amistad sin que ellos ni nadie pudieran evitarlo ${ }^{63}$.

El 28 de mayo de 1823, en la villa de Xalapa, hubo la primera reunión entre las dos delegaciones. En ella acordaron «tratar de combinar los intereses de ambos gobiernos y consolidar por este medio las muy estrechas relaciones de paz, confraternidad e íntima alianza a que la naturaleza mutuamente los invita». Pero la tensión dominó la reunión una vez que el general Victoria directamente les preguntó si estaban «autorizados para reconocer la independencia de la Nación Mexicana, su libertad, la integridad de su territorio, la forma de gobierno» y a referirse a ella en futuro, no como país, como venían haciéndolo, sino a la «Nación Mexicana». De no ser así, no habría diálogo. En este primer acercamiento no se llegó a ningún acuerdo porque los comisionados no aceptaron la petición bajo el argumento de no serles «posible excederse de sus poderes contenidos en las credenciales» ${ }^{64}$. A día siguiente el general Victoria hizo la misma pregunta y los españoles se negaron terminantemente a utilizar el término de «Nación Mexicana» porque consideraban que

${ }^{62}$ Carta de Juan Ramón Osés a Guadalupe Victoria, Castillo de San Juan de Ulúa, 20 de abril de 1823; y Carta de Guadalupe Victoria a Juan Ramón Osés, Veracruz, 21 de abril de 1823, AHSRE, vol. 1-F 2183.

${ }^{63}$ Carta de Francisco Lemaur, a Juan Ramón Osés, Santiago Irrizarri y Blas Osés, San Juan de Ulúa, 13 de mayo de 1823, AGI, Estado, leg. 35, n. ${ }^{\circ}$ 93. Carta de Juan Ramón Osés, Santiago Irrizarri y Blas Osés al Secretario de Estado y de la Gobernación de Ultramar, Xalapa, 1 de agosto de 1823, AGI, Estado, leg. 35 n. ${ }^{\circ} 94$.

${ }_{64}^{64}$ Acta de los acuerdos reservados, Xalapa, 12 de junio de 1823, AGI, Estado, leg. 35, n. ${ }^{\circ} 94$. 
al darle este nombre «era ya suponer reconocida su independencia». Entonces Victoria propuso se sustituyera por la palabra «continente», la que calificaron de un «despropósito geográfico» porque no se trataba de toda la América. Al final se aceptó este término en el entendido de que no se incluía a San Juan de Ulúa ${ }^{65}$. Al final, ambas delegaciones acordaron firmar sólo convenios provisionales relacionados con el comercio ${ }^{66}$.

En ningún momento los comisionados españoles informaron de los acuerdos alcanzados al gobernador Lemaur por ser enemigo de la Constitución. Cuando éste los conoció, de inmediato los rechazó al considerar que los «comisionados pacificadores», desde un principio no manifestaron la imposibilidad del reconocimiento de la independencia ${ }^{67}$. Lemaur y sus partidarios se quedaron sin posibilidad alguna de interlocución con las autoridades de Veracruz. Militares, políticos y comerciantes españoles habían sido relegados por completo. En cambio, el gobierno nacional, el ejército, la Diputación Provincial y el Ayuntamiento porteño, hicieron un frete común para bloquear las comunicaciones con la fortaleza de san Juan de Ulúa. Las negociaciones se interrumpieron cuando se conoció la noticia de la disolución del gobierno liberal en España, al que representaban los comisionados, y el restablecimiento del absolutismo de Fernando VII. En cuanto corrió la noticia, los españoles que todavía estaban en la ciudad como pudieron se embarcaron hacia el castillo en busca de protección ${ }^{68}$.

Así como O’Donojú había respondido a su ideología liberal, Lemaur hizo lo mismo al decidir el bombardeo de la ciudad, una vez confirmada la noticia de que la Santa Alianza había declarado la guerra al gobierno liberal de España y apoyaba la restitución de Fernando VII como rey absoluto. La noche del 23 septiembre de 1823, los jefes y oficiales españoles de la fortaleza de Ulúa se reunieron en junta de guerra con el fin de analizar la situación para

${ }^{65}$ Acta de los acuerdos reservados, Xalapa, 13 de junio de 1823, AGI, Estado, leg. 35, n. ${ }^{\circ} 94$.

${ }^{66}$ Acta de los acuerdos reservados, Xalapa, 14 de junio de 1823 y Acta de los acuerdos reservados, Xalapa, 18 de junio de 1823, AGI, Estado, leg. 35, n. ${ }^{\circ} 94$.

${ }^{67}$ Carta de Francisco Lemaur al Secretario de estado y del Despacho de la Gobernación de Ultramar, San Juan de Ulúa, 14 de julio de 1823, AGI, Estado, leg. 35, n. ${ }^{\circ} 74$.

${ }_{68}$ Carta de Victoria al Gobierno de Veracruz, Xalapa, 10 de septiembre de 1823, AHSDN, exp. 209, f. 28. Carta de Victoria al Ministro de Guerra, Veracruz, 15 y 22 de octubre de 1823, AHSDN, exp. 210, f. 11. Entre éstos se encontraban Manuel Grijalva (diputado electo para el siguiente Congreso), Cayetano Canaleta, Ignacio Candaya, José Guilbert, Francisco Emparán con su familia, Pedro Carazo, Manuel Martínez Sampeiro, Vicente Uriarte con su familia, Joaquín Tajonar, Joaquín Gómez, Francisco Uriarte, Manuel Larumbe e hijos, Pedro Campos y Francisco Fonteche. La mayoría de ellos se embarcaron con rumbo a La Habana. A todos ellos se les incautaron sus propiedades en México. 
enfrentar la crisis que se venía ante el cierre de su comercio. La mayoría de ellos resolvieron: Intimidar a la plaza para obligarla a abrir el puerto, se permitiera la comunicación con el castillo, se suspendieran las obras de fortificación de la ciudad y se retiraran las baterías de Mocambo que le apuntaban ${ }^{69}$. Mientras en Xalapa los comisionados de las Cortes Españolas todavía negociaban el tratado comercial con los representantes mexicanos, el general Lemaur iniciaba el bombardeo sobre la ciudad, con funestas consecuencias para ambos bandos. Según Reynaldo Sordo, la guerra comenzó cuando los borbonistas quedaron marginados y hasta excluidos de los debates en el Congreso Constituyente sobre la forma de gobierno ${ }^{70}$.

La última participación de Lemaur y de los defensores del absolutismo en los asuntos internos de México se dio en enero de 1824. Por medio de sus «agentes» promovió una nueva revolución contra el «alma» del Poder Ejecutivo de la Nación, es decir, de Mariano Michelena, que en ese momento tenía a su cargo la oficina por ausencia del triunvirato conformado por Guadalupe Victoria, Nicolás Bravo y Pedro Celestino Negrete. Se decía que Michelena era el principal enemigo de los españoles. Él, que había sido oficial del ejército realista, diputado a las Cortes Españolas, «es aquí uno de los más ardientes campeones de la independencia y acérrimo enemigo de nuestro nombre y aún más de la dominación española. Convenía pues derrumbar a este poderoso contrario». Tres de los principales agentes recomendaron al general José María Lobato para que encabezara el nuevo pronunciamiento ${ }^{71}$. Éste aceptó la invitación, pero una vez pronunciado, «para darle una mejor acogida lo varió agregando entre otras cosas la petición de expulsar de los cargos públicos también a los españoles» ${ }^{72}$, e hizo fracasar el proyecto.

Para entonces, muchos oficiales peninsulares ya estaban avisados del nuevo plan y comprometidos para secundarlo, pero los cambios hechos por el mismo Lobato, obligó a los propios conspiradores a moverse con rapidez dando «aviso al gobierno de lo que contra él se tramaba» y persuadiendo a los oficiales para que no salieran a las calles. De esta manera se «abortó así la conjuración [sic] capitaneada por Lobato, habiendo dado tiempo para ganar y disuadir a muchos de los oficiales conjurados». El resultado final fue que

${ }^{69}$ Extracto de lo que resulta perteneciente al sitio y defensa del Castillo de San Juan de Ulúa, del diario de México, titulado El Sol, desde 5 de octubre de 1823 hasta 20 de diciembre del mismo, AHMM, caja 102.

${ }^{70}$ Sordo, 2003: 129.

71 El general José María Lobato primero combatió a los insurgentes y en 1811 cambió de bando en el que militó hasta 1821 en que se unió al Ejército Trigarante.

72 Carta de Francisco Lemaur, al Secretario de estado y del Despacho de la Gobernación de Ultramar, San Juan de Ulúa, 13 de abril de 1824, AGI, Estado, leg. 35, n. ${ }^{\circ} 80$. 
varios recularon y lograron quedar a salvo; otros fueron perdonados junto con Lobato a partir de las negociaciones y hasta premio recibieron. En cambio, los soldados que optaron por continuar con el plan fueron detenidos y su jefe el teniente José Stávoli, fue sentenciado a la pena máxima, misma que fue conmutada por destierro ${ }^{73}$. De los cronistas de la época, sólo Bustamante hizo referencia a la intención de Lobato de acabar con el gobierno encabezado por Michelena, pero nadie registró la participación de los absolutistas.

Ante el abandono en que quedaron las tropas españolas de san Juan de Ulúa y sin la posibilidad de resistir el asedio por más tiempo, el 18 de noviembre de 1825 debieron capitular. Al mismo tiempo, en la ciudad de México el Congreso Constituyente se reunía por segunda vez para elaborar la primera Constitución republicana de los Estados Unidos Mexicanos, misma que entró en vigor el 4 de octubre de 1824.

\section{REFLEXIÓN FINAL}

Los enfrentamientos políticos y armados para imponer una forma de gobierno, bien fuera monárquico o imperial con un miembro de las casas reinantes de Europa, así como el republicano federal o central y hasta la dictadura militar, tenían como trasfondo el modelo de sociedad: el basado en privilegios y sistema de casta, como en la época colonial, y la republicana liberal que pugnaba por la igualdad social ante la ley. Los intentos de reconquista española siempre contaron con el aval de los grupos conservadores mexicanos y del clero. La Constitución mexicana de 1857, por un lado, y la invasión francesa y posterior proclamación de Maximiliano como emperador de México, por el otro, expresaron con precisión las posturas antes señaladas. Al final, fue el fusilamiento del emperador en 1867 el que canceló cualquier posibilidad de insistir en la permanencia de una sociedad basada en la exclusión y no en la igualdad social. El fantasma del modelo monárquico de gobierno para México no cesó durante las siguientes décadas.

${ }^{73}$ Idem. Alamán, 1985, t. 5: 779-782. Fueron arrestados los coroneles Pedro María Gil, Dionisio Mori y Feliciano Rodríguez; los capitanes, Andrés Esparza, Mariano Infazón, José María Alcocer, Nicolás Melgarejo, Rafael Saavedra, Miguel Ortega y Mora, Juan Nepomuceno Cervantes, Santiago Rodríguez y José María Barberi; el teniente coronel José Stávoli; los tenientes Enrique Aparicio, Luciano Muñoz, Andrés Cervantes, José Cayo Navarro, e Ignacio Barberi; el capitán graduado de coronel Juan Ordaza; el capitán retirado Antonio del Río, y los tenientes José Jiménez y José Osorio. Vázquez, Hernández Silva y Bustamante, 2021, CD-1, 27 de enero de 1824. 
En enero de 1827 fue descubierta la primera conspiración monárquica del periodo republicano. La encabezaba el fraile dieguino de origen español, Joaquín de Arenas, y en ella estaban involucrados varios generales, también de origen español, como Pedro Celestino Negrete y José Antonio de Echávarri. La conspiración fue descubierta ante la osadía e imprudencia de Arenas al invitar al levantamiento militar al Comandante General de México, el general Ignacio Mora Villamil. En el Plan se reconocía la monarquía de la casa de Borbón y la religión católica; a los exinsurgentes Vicente Guerrero y Guadalupe Victoria debían detenérseles siempre y cuando no apoyasen el Plan. Se aseguró que ya se encontraba en la ciudad de México un comisionado regio para ocuparse del cambio de gobierno. Arenas murió fusilado el 2 de junio de 1827; en cambio, Negrete y Echávarri fueron enviados al exilio.

Tiempo después se supo que en 1827 el infante Francisco de Paula había intentado proclamarse emperador de México; para ello había buscado la anuencia de los gobiernos de Reino Unido y Francia. De hecho, para mayo de 1828 ya había hecho varios nombramientos: el barón Cayllerand iba a ocupar el ministerio de negocios extranjeros; al duque de Dino, par de Francia, le nombró comandante general del ejército que se iba a formar para la ocupación de México, y al vizconde de Astier le nombró «corona del estado mayor de México». El proyecto no se concretó ante la negativa del monarca Fernando VII que ya preparaba una expedición para la reconquista de su antigua colonia. Así fue como el 26 de julio de 1829 desembarcaron en las costas mexicanas las tropas encabezadas por el brigadier Isidro Barradas, quien fracasó en el intento. Sus tropas fueron completamente derrotadas ${ }^{74}$. El monarca Fernando VII nunca reconoció la independencia de México; fue la regente María Cristina quien finalmente lo hizo en 1836.

En 1840 produjeron un gran escándalo una notas periodísticas publicada por José María Gutiérrez de Estada en las que aseguraba que México no había hombres preparados para gobernar, por lo que había que llamar a un monarca extranjero, de preferencia de la casa de Borbón. Luego, en 1845, el nuevo embajador español Salvador Bermúdez de Castro comenzó a intervenir de una manera directa en la política mexicana para restablecer la monarquía española. Para ello se puso en comunicación con uno de los hombres más influyentes del momento, el general Marino Paredes y Arrillaga que entonces se encontraba en San Luis Potosí con 12.000 efectivos del ejército de reserva para combatir a los texanos. También estaban involucrados, entre otros, los generales Gabriel Valencia y Nicolás Bravo. En vez de marchar hacia el norte regresó a la ciudad de México para dar un golpe de Estado y formar una

\footnotetext{
${ }^{74}$ Frasquet, 2002: 115-132.
} 
junta de notables por los hombres más poderosos del país y sin la representación popular. Su idea era retomar los principios básicos del Plan de Igual ${ }^{75}$. Pero su proyecto se vino abajo ante la ofensiva federalista y el restablecimiento de la Constitución de 1824. Al mismo tiempo, Gran Bretaña, Francia y España negociaban el establecimiento de una monarquía en México y comenzaron a barajar nombres de posibles candidatos. Ya no importaba tanto que el monarca para México fuera español, simplemente que el designado gozara del beneplácito de las tres potencias.

\section{BiBLIOGRAFía}

Aguilar, José Antonio y Rojas, Rafael (coord.), El republicanismo en Hispanoamérica. Ensayos de historia intelectual y política, México, FCE, 2002.

Alamán, Lucas, Historia de México desde los primeros movimientos que prepararon su independencia en el año de 1808 hasta la época presente, México, Fondo de Cultura Económica, Instituto Cultural Helénico, 1985, tomo 5.

Anna, Timothy E., El imperio de Iturbide, México, CONACULTA/Alianza Editorial, 1991.

Annino, Antonio, La revolución novohispana, 1808-1821, México, Fondo de Cultura Económica, 2010.

Archer, Christon I., "Las tropas expedicionarias españolas en la guerra de independencia de México, 1810-1822", Juan Ortiz Escamilla (coord.), Revisión histórica de la guerra de independencia en Veracruz, Xalapa, Comisión para la Conmemoración de la Independencia Nacional y de la Revolución Mexicana/Universidad Veracruzana/Gobierno del Estado de Veracruz, 2008: 197-228.

Arenal del Fenochio, Jaime, Unión, Independencia, Constitución. Nuevas reflexiones en torno a un modo de ser libres, México, INEHRM, 2010.

Ávila, Alfredo, "Conspiradores y sociedades secretaras. Veracruz y Xalapa, 18081812", Juan Ortiz Escamilla (coord.), Revisión histórica de la guerra de independencia en Veracruz, Xalapa, Comisión para la Conmemoración de la Independencia Nacional y de la Revolución Mexicana/Universidad Veracruzana/Gobierno del Estado de Veracruz, 2008: 161-175.

Ávila, Alfredo, Ortiz Escamilla, Juan, Serrano, José Antonio y Florescano, Enrique (coord.), Actores y escenarios de la Independencia. Guerra, pensamiento e instituciones, 1810-1825, México, FCE/Museo Soumaya/Fundación Carlos Slim, 2010.

75 Villavicencio, 2015: 144-145. 
Breña, Roberto, El primer liberalismo español y los procesos de emancipación de América, 1808-1824. Una revisión historiográfica del liberalismo hispánico, México, El Colegio de México, 2006.

Breña, Roberto (ed.), Cádiz a debate: actualidad, contexto y legado, México, El Colegio de México, 2014.

Carbajal López, David, "Clérigos y frailes en Veracruz ante la guerra de 1810", Juan Ortiz Escamilla (coord.), Revisión histórica de la guerra de independencia en Veracruz, Xalapa, Comisión para la Conmemoración de la Independencia Nacional y de la Revolución Mexicana/Universidad Veracruzana/Gobierno del Estado de Veracruz, 2008: 229-254.

Chust Calero, Manuel, "Federalismo avant la letre en las Cortes Hispanas, 18101821 ”, Josefina Zoraida Vázquez (coord.), El establecimiento del federalismo en México (1821-1827), México, El Colegio de México, 2003: 77-114.

Chust Calero, Manuel (coord.), 1812. El poder de la palabra. América y la Constitución de 1812, España, Edición Cultural Española/Consorcio para la Conmemoración del II Centenario de la Constitución de 1812/Lunwerg Editores, 2012.

Chust Calero, Manuel y Serrano Ortega, José Antonio, Tras la guerra, la tempestad. Reformismo borbónico, liberalismo doceañista y federalismo revolucionario en México (1780-1835), Madrid, Universidad de Alcalá/Marcial Pons, 2019.

Ducey, Michael T., "Violencia, poder y gobierno. La administración insurgente en los pueblos indígenas de la costa de Barlovento, 1812-1820" Juan Ortiz Escamilla (coord.), Revisión histórica de la guerra de independencia en Veracruz, Xalapa, Comisión para la Conmemoración de la Independencia Nacional y de la Revolución Mexicana/ Universidad Veracruzana/Gobierno del Estado de Veracruz, 2008: 123-140.

Fernández, Delfina, Últimos reductos españoles en América, Madrid, Mapfre, 1992. Colección Armas y América, 7.

Fowler, Will, Santa Anna, Xalapa, Universidad Veracruzana, 2010.

Frasquet, Ivana, "Milicianos y soldados. La problemática social mexicana en la invasión de 1829", Salvador Broseta, Carmen Corona, Manuel Chust et al. (eds.), Las ciudades y la guerra, 1750-1898, Castellón de la Plana, Universitat Jaume I, 2002: 115-132.

Frasquet, Ivana, Las caras del águila. Del liberalismo gaditano a la república federal mexicana (1820-1824), Castellón de la Plana, Universitat Jaume I, 2008.

Gil Maroño, Adriana, “¿De vasallos a ciudadanos? Los comerciantes de la ciudad de Veracruz entre el antiguo régimen y el liberalismo gaditano", Juan Ortiz Escamilla (coord.), Revisión histórica de la guerra de independencia en Veracruz, Xalapa, Comisión para la Conmemoración de la Independencia Nacional y de la Revolución Mexicana/Universidad Veracruzana/Gobierno del Estado de Veracruz, 2008: 99-122. 
Grafenstein von, Johanna, "Las pequeñas radas de la costa veracruzana y su papel durante la guerra", Juan Ortiz Escamilla (coord.), Revisión histórica de la guerra de independencia en Veracruz, Xalapa, Comisión para la Conmemoración de la Independencia Nacional y de la Revolución Mexicana/Universidad Veracruzana/ Gobierno del Estado de Veracruz, 2008: 141-160.

Gutiérrez Casillas, José, Papeles de Agustín de Iturbide, México, Tradición, 1977.

Herrejón Peredo, Carlos (comp.), Guadalupe Victoria: documentos, México, Instituto Nacional de Estudios Históricos de la Revolución Mexicana, 1986.

Jáuregui, Luis, "La Real Aduana de Veracruz durante la guerra de independencia" Juan Ortiz Escamilla (coord.), Revisión histórica de la guerra de independencia en Veracruz, Xalapa, Comisión para la Conmemoración de la Independencia Nacional y de la Revolución Mexicana/Universidad Veracruzana/Gobierno del Estado de Veracruz, 2008: 35-51.

Jiménez Codinach, Estela Guadalupe, La Gran Bretaña y la independencia de México 1808-1821, México, FCE, 1991.

Moreno Gutiérrez, Rodrigo, La Trigarancia. Fuerzas armadas en la consumación de la independencia. Nueva España, 1820-1821, México, UNAM, 2016.

Ortiz Escamilla, Juan, El teatro de la guerra. Veracruz 1750-1825, Castellón de la Plana, Universitat Jaume I, 2008a.

Ortiz Escamilla, Juan, "Los gobiernos realistas de Veracruz", Juan Ortiz Escamilla (coord.), Revisión histórica de la guerra de independencia en Veracruz, Xalapa, Comisión para la Conmemoración de la Independencia Nacional y de la Revolución Mexicana/Universidad Veracruzana/Gobierno del Estado de Veracruz, 2008b: 177-196.

Ortiz Escamilla, Juan, Guerra y gobierno. Los pueblos y la independencia de México, 1808-1825, Segunda Edición corregida y aumentada, México, El Colegio de México/Instituto Mora, 2014.

Ortiz Escamilla, Juan y Serrano Ortega José Antonio (eds.), Ayuntamientos y liberalismo gaditano en México, Zamora, El Colegio de Michoacán/Universidad Veracruzana, 2007.

Palacio, Celia del, "La independencia en la prensa de Veracruz", Juan Ortiz Escamilla (coord.), Revisión histórica de la guerra de independencia en Veracruz, Xalapa, Comisión para la Conmemoración de la Independencia Nacional y de la Revolución Mexicana/Universidad Veracruzana/Gobierno del Estado de Veracruz, 2008: 255-293.

Rozat Dupeyron, Guy, "La nación entre memoria e historia. La independencia como discurso pedagógico de la nación”, Juan Ortiz Escamilla (coord.), Revisión histórica de la guerra de independencia en Veracruz, Xalapa, Comisión para la Con- 
memoración de la Independencia Nacional y de la Revolución Mexicana/Universidad Veracruzana/Gobierno del Estado de Veracruz, 2008: 17-34.

Saucedo Zarco, Carmen, "La convención de las Provincias Orientales. Un proyecto de gobierno insurgente", José Antonio Serrano Ortega (coord.), El sexenio absolutista. Los últimos años insurgentes. Nueva España (1814-1820), México, El Colegio de Michoacán, 2014: 375-396.

Serrano, José Antonio y Chust, Manuel, "Veracruz: antiguo régimen, liberalismo gaditano e independencia, 1750-1826" Juan Ortiz Escamilla (coord.), Revisión histórica de la guerra de independencia en Veracruz, Xalapa, Comisión para la Conmemoración de la Independencia Nacional y de la Revolución Mexicana/ Universidad Veracruzana/Gobierno del Estado de Veracruz, 2008: 73-98.

Sordo, Reynaldo, "El Congreso Nacional: de la autonomía de las provincias al compromiso federal", Josefina Zoraida Vázquez, El establecimiento del federalismo en México (1821-1827), México El Colegio de México, 2003: 115-153.

Souto Mantecón, Matilde, La política y el comercio del Consulado de Veracruz en el ocaso del sistema imperial, México, El Colegio de México/Instituto Mora, 2001.

Tecuanhuey, Alicia, "Tras las trincheras del federalismo. Intereses y fuerzas regionales en Puebla, 1823-1825", Josefina Zoraida Vázquez (coord.), El establecimiento del Federalismo en México (1821-1827), México, El Colegio de México, 2003: 476-484.

Terán, Mariana, "De cántaros y juramentos. El trienio liberal en Zacatecas", Ana Carolina Ibarra, Juan Ortiz Escamilla y Alicia Tecuanhuey (coords.), Herrejón: su legado, Xalapa, Universidad Veracruzana/UNAM/El Colegio de Michoacán/ BUAP, 2020.

Valle Pavón, Guillermina del, "El monopolio del tabaco en Veracruz durante la guerra de independencia", Juan Ortiz Escamilla (coord.), Revisión histórica de la guerra de independencia en Veracruz, Xalapa, Comisión para la Conmemoración de la Independencia Nacional y de la Revolución Mexicana/Universidad Veracruzana/Gobierno del Estado de Veracruz, 2008: 53-71.

Vázquez, Josefina Zoraida, Hernández Silva, Héctor Cuauhtémoc y Bustamante, Carlos María de (eds.), Diario Histórico de México de Carlos María de Bustamante, México, El Colegio de México/Centro de Investigaciones y Estudios Superiores en Antropología Social, 2001, 2 discos compactos.

Villavicencio, Víctor Alberto, El camino del monarquismo mexicano decimonónico: momentos, proyectos y personajes, tesis de doctorado, México, Universidad Nacional Autónoma de México, 2015.

Fecha de recepción: 18 de mayo de 2020.

Fecha de aceptación: 9 de septiembre de 2020. 


\section{Veracruz: monarchy, empire or republic}

This is a study on government proposals and experiments in Mexico between 1820 and 1824. With the re-establishment of the Cadiz Constitution, the absolutist monarchy became a constitutional one. Once Mexico gained independence under the conservative Plan de Iguala, the new nation remained subordinate to the Spanish monarchy. The whole project then collapsed due to a rift among its followers, eliminating the so-called Mexican Empire which gave way to the beginning of the First Mexican Federal Republic.

KeY words: Mexico; Independence; Empire; Republic; Monarchy. 